\title{
Commentary: Supporting patient independence in long term haemodialysis
}

\author{
Tania Barnes clinical nurse educator ${ }^{1}$, Michael Winfrow home haemodialysis patient ${ }^{2}$, Paul Laboi \\ consultant nephrologist ${ }^{3}$, Martin Wilkie consultant nephrologist ${ }^{1}$
}

${ }^{1}$ Sheffield Teaching Hospitals, Sheffield, UK; ${ }^{2}$ Sheffield, UK; ${ }^{3}$ York Teaching Hospitals, York, UK

Around 20000 people in the UK are dependent on dialysis. It's a demanding procedure, usually taking three to four hours, three times a week. Unsurprisingly, it disrupts people's lives and can have a major effect on their wellbeing. Historically, there has been little opportunity for people to play an active part in managing their care, and patients often experience treatment as inflexible, demotivating, and disempowering.

We observed this in our dialysis unit and also saw people who we knew were capable of taking care of themselves. This led us to introduce a programme of shared care for haemodialysis patients across the Yorkshire and the Humber region in 2010, with support from the Health Foundation.

The programme is based on fostering a new partnership with patients and supporting them to take on components of their dialysis treatment. Patients choose which tasks they want to take on and the pace at which they do so. This allows them to be in control and build confidence over time. The programme adapts to a range of learning styles and individual abilities and is open to all.

The programme also involves teaching dialysis nurses new skills needed to support patients to self manage. Staff are challenged to rethink their professional role and to understand their individual learning style and which approaches result in good (and bad) educational experiences. This helps staff understand patients' perspectives and how best to support them.

The results have been striking. Patients have reported greater control over their illness, increased confidence, and feeling more able to ask questions about their treatment (box). ${ }^{1}$ Dialysis staff are positive too. One stated, "I have learnt how to change people's thinking without coercion." Up to $40 \%$ of patients in our centres undertake five or more aspects of their dialysis care, and in assessments around $75 \%$ of patients said they had been asked if they would like to participate in shared care and a similar proportion would recommend shared care to other patients. We have made our teaching resources publically available, and the shared haemodialysis care programme has been adopted by several units across the UK.
Time is always cited as one barrier to promoting shared care. Our approach has been to incorporate patient education into the daily routine - for example, by explaining while performing a task. Patients are often concerned that if they get involved they will have to do home dialysis. It is clearly important to reassure them that the choice to dialyse at home is theirs and not all will want this. Shared haemodialysis care does require flexibility in units where traditionally services have been set up to "do things to patients." Treating patients as true partners in care from their earliest attendance at the renal outpatient department helps embed a participatory approach.

Low health literacy among patients requiring haemodialysis is a marker of increased mortality. ${ }^{2}$ Patient training has the potential to improve the situation, and indeed outcomes for home haemodialysis are better than for other dialysis treatments. ${ }^{3}$ We believe that all patients on dialysis should be offered the opportunity to perform their own dialysis if they wish to.

Competing interests: We have read and understood BMJ policy on declaration of interests and have no relevant interests to declare.

Further information about the shared haemodialysis care programme is available at www.shareddialysis-care.org.uk/ and in Paul Laboi's blog http://blogs.bmj.com/bmj/2014/11/21/paul-laboi-making-dialysis-caremore-person-centred/.

Provenance and peer review: Commissioned; not externally peer reviewed.

Glidewell L, Boocock S, Pine K, Campbell R, Hackett J, Gill S, et al Using behavioural theories to optimise shared haemodialysis care: a qualitative intervention development study of patient and professional experience. Implement Sci 2013;8:118.

2 Cavanaugh KL, Wingard RL, Hakim RM, Eden S, Shintani A, Wallston KA, et al. Low health literacy associates with increased mortality in ESRD. J Am Soc Nephrol 2010:21:1979-85.

3 Nitsch D, Steenkamp R, Tomson CR, Roderick P, Ansell D, MacGregor MS. Outcomes in patients on home haemodialysis in England and Wales, 1997-2005: a comparative cohort analysis. Nephrol Dial Transplant 2011;26:1670-7. 


\section{My experience of care-Michael Winfrow}

Shared care happened slowly at first, and this bit by bit approach was helpful—starting with learning to measure blood pressure and weight, to collect the needles and syringes; the learning was reinforced at each visit. However, I felt more anxious when it came to self needling. I was initially hesitant, and there was some bleeding down my arm because I was slow to insert the needle; this made me more nervous. Although the first needle was straight forward, the second needle was more problematic. Eventually I overcame this through persistence and the practical advice and support that I received.

So how does shared care help patients? Firstly, it gives you your independence back. It makes you think you are part of the team looking after you. It also helps you to understand your illness better because it puts you in close contact with people looking after you-for example when programming your dialysis machine you can ask questions about what affects your blood results, etc. When you have a better understanding of your illness you can become more involved-for instance, finding out whether a problem is better controlled by diet or medication.

As my knowledge and confidence grew I started to ask about home haemodialysis, which gives you more freedom. The shared haemodialysis care programme gave me the confidence to take this next step.

I thought really hard about what could be negative; however, this is a scheme where you can do as much or as little as you want. So if you are fazed by programming your machine, then you don't do that part of your care; also everything is checked by the nursing staff, giving you the reassurance that everything is safe and correct. It says in the shared care handbook you will not be pressured into doing anything beyond your wishes or capabilities. 